\title{
Radiologie in de lift...
}

Citation for published version (APA):

Wilmink, J. T. (2008). Radiologie in de lift... Afscheidsrede van J.T. Wilmink. (1 ed.) Universiteit Maastricht. https://doi.org/10.26481/spe.20080101jw

Document status and date:

Published: 01/01/2008

DOI:

10.26481/spe.20080101jw

Document Version:

Publisher's PDF, also known as Version of record

\section{Please check the document version of this publication:}

- A submitted manuscript is the version of the article upon submission and before peer-review. There can be important differences between the submitted version and the official published version of record.

People interested in the research are advised to contact the author for the final version of the publication, or visit the DOI to the publisher's website.

- The final author version and the galley proof are versions of the publication after peer review.

- The final published version features the final layout of the paper including the volume, issue and page numbers.

Link to publication

\footnotetext{
General rights rights.

- You may freely distribute the URL identifying the publication in the public portal. please follow below link for the End User Agreement:

www.umlib.nl/taverne-license

Take down policy

If you believe that this document breaches copyright please contact us at:

repository@maastrichtuniversity.nl

providing details and we will investigate your claim.
}

Copyright and moral rights for the publications made accessible in the public portal are retained by the authors and/or other copyright owners and it is a condition of accessing publications that users recognise and abide by the legal requirements associated with these

- Users may download and print one copy of any publication from the public portal for the purpose of private study or research.

- You may not further distribute the material or use it for any profit-making activity or commercial gain

If the publication is distributed under the terms of Article $25 \mathrm{fa}$ of the Dutch Copyright Act, indicated by the "Taverne" license above, 


\section{Universiteit Maastricht}

\section{J. T. Wilmink}

\section{'Radiologie in de lift...'}

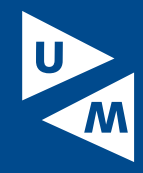



Radiologie in de lift... 


\section{Colofon}

Ontwerp en print: Océ Business Services, Maastricht

ISBN: $978-90-5681-293-5$

NUR: 870

Alle rechten voorbehouden. Niets uit deze uitgave mag worden verveelvoudigd, opgeslagen in een geautomatiseerd gegevensbestand of openbaar gemaakt worden, zonder voorafgaande schriftelijke toestemming van de auteur of uitgever. 


\section{Radiologie in de lift...}

Afscheidsrede van J.T. Wilmink

Maastricht University 
Geachte Rector Magnificus, dames en heren,

De titel van deze voordracht is voor tweeërlei uitleg vatbaar. Een lift kan namelijk stijgen, maar ook dalen.

Voor vele aspecten van mijn vakgebied is het verhaal positief.

Ik heb gewerkt in een tijd van ongelofelijke ontwikkelingen. In andere opzichten dreigen er donkere wolken op de horizon.

Ik begin met een terugblik op de afgelopen 18 jaren in en buiten Maastricht. Gedreven door de technische voortgang en de enorme uitbreiding van materiële middelen is er in deze periode een volumetoename ontstaan welke onze manier van werken ingrijpend heeft veranderd. In de toekomst zou zelfs de radiologie ten onder kunnen gaan aan haar eigen succes.

Voor de uitgangssituatie ga ik terug naar de rede welke ik heb uitgesproken in 1992, bij de aanvaarding van het ambt van buitengewoon hoogleraar in de neuroradiologie.

De titel van deze rede, "Oude en nieuwe kopzorgen" geeft aan dat er toen ook al sprake was van een betoog met nuance. Dat is nog steeds het geval.

In November 1990 begon met ik mijn werkzaamheden in Maastricht. De verhuizing vanuit het oude Annadal ziekenhuis naar het toen gloednieuwe AZM gebouw in Randwyck, stond voor de deur. Het MRI apparaat in de nieuwbouw was al bedrijfsgereed, en het was een aparte ervaring om in een gigantisch maar bijna spookachtig leeg gebouw, met de MRI ploeg van het eerste uur bestaande uit de laboranten Evelien Peters, Henk Schoenmakers en Geert Wijnhoven, en samen met Riël Snoep de eerste patiënten op te vangen en te onderzoeken, procedures en protocollen te ontwikkelen.

Terugblikkend op die tijd, kunnen wij zien dat de MRI, magnetic resonance imaging, oftewel de beeldvorming gebaseerd op kernspinresonantie, de kinderschoenen was ontgroeid. Het principe was al veel langer bekend, maar pas in de tweede helft van de tachtiger jaren werd deze zeer geavanceerde techniek op grote schaal toegepast in de klinische diagnostiek, naast het oudere broertje: de röntgencomputertomografie $\mathrm{CT}$, waarmee ongeveer tien jaren eerder het tijdperk van de digitale beeldvorming was geopend. 
In Randwyck stond eind 1990 één MRI scanner opgesteld, veldsterkte 0,5 Tesla. Wij trokken per patiënt 45 minuten scantijd uit, en de productie in het eerste volle bedrijfsjaar 1991 bedroeg 2010 MRI verrichtingen, voor $85 \%$ z.g. "neuro" onderzoeken van de hersenen en van de wervelkolom. Momenteel telt Nederland meer dan honderd MRI systemen, deze zijn nu zelfs in de kleinere perifere ziekenhuizen aan te treffen. De grotere ziekenhuizen hebben doorgaans meerdere scanners. In het Academisch Ziekenhuis Maastricht zijn thans drie MRI scanners in bedrijf onder beheer van de vakgroep Radiologie, twee met een veldsterkte van 1,5 Tesla, en één systeem met een nog hogere veldsterkte van 3 Tesla. De jaarproductie van onze vakgroep bedroeg in 2007 met drie scanners ruim $10.000 \mathrm{MRI}$ onderzoeken; meer dan vijfmaal zoveel als met één scanner in 1991, dit ondanks het feit dat van één van onze drie scanners de helft van de scancapaciteit wordt ingezet voor research. Het aandeel van de "neuro" onderzoeken van hersenen en wervelkolom is gedaald naar ongeveer 50\% doordat b.v. hoofd-hals diagnostiek, beeldvorming van hart en bloedvaten, van het bewegingsapparaat, en ook abdominale diagnostiek zijn toegevoegd aan het MRI indicatiegebied.

De stijging in productie van MRI onderzoeken is toe te schrijven aan meerder factoren: kortere onderzoekstijden door de rationalisatie van scanprotocollen, waarbij de bijdrage van de laborantengroep van groot belang is, en ook uitbreiding van de bedrijfsuren. Vroeger bleef buiten de kantooruren de magneet van de scanner weliswaar aanstaan maar er werden geen patiënten onderzocht. Nu is het door personeelsuitbreiding ook mogelijk geworden om in de avonduren en in de weekeinden patiëntenonderzoeken uit te voeren. Vooral dit laatste heeft in het jaar 2007, vergeleken met 2006, geresulteerd in een stijging in het aantal gescande patiënten met maar liefst $20 \%$ !.

Hierbij moeten dan wel twee kanttekeningen worden gezet:

Ten eerste: de uitbreiding van de bedrijfstijden was vooral gemotiveerd door zorg over de lengte van de wachtlijsten voor MRI, welke waren opgelopen tot enkele weken en soms zelfs maanden. Na de verwachte aanvankelijke daling van de wachttijden door de capaciteitsuitbreiding begonnen deze echter al snel weer op te lopen in de richting van het oude niveau, door toename van het aantal aanvragen voor MRI. Eén mogelijke verklaring hiervoor is dat patiënten van het AZM die vanwege de lengte van de wachtlijst voor MRI waren uitgeweken naar andere ziekenhuizen over de Belgische grens, nu weer zijn teruggekeerd. Een alternatieve verklaring zou kunnen zijn dat thans gemakkelijker wordt 
overgegaan tot het aanvragen van een MRI onderzoek.

Ten tweede: MRI productie bestaat niet alleen uit het scannen van patiënten. Het onderzoek moet worden beoordeeld door een deskundige radioloog, en deze beoordeling moet worden bericht aan de verwijzende clinicus. Dit gebeurt in de vorm van een schriftelijk verslag, eventueel aangevuld met mondelinge mededelingen, telefonisch of tijdens een multidisciplinaire patiëntenbespreking. Verslaglegging en bespreking zijn beide behoorlijk tijdrovend maar essentieel voor de kwaliteit van het product als geheel, en het simpelweg vergroten van de scancapaciteit zonder ook de verwerkingscapaciteit in dezelfde mate uit te breiden lost het probleem niet op. Wij kunnen een vergelijking maken met de fileproblematiek: na het oplossen van één knelpunt verplaatst de file zich naar elders.

Hierover later meer.

Vroeger was het leven van de MRI radioloog relatief eenvoudig en overzichtelijk, met een beperkt aantal keuzemogelijkheden in beelden. Er was een beeld met z.g. T1 contrast: Hierin was het aanwezige vet helder wit afgebeeld, en het T1 gewogen beeld heette dan ook het "vetplaatje". Verder was er een T2 gewogen beeld waarin het vocht in bepaalde organen zoals glasvocht in de oogbol, hersenvocht in en om het centrale zenuwstelsel, maar ook b.v. urine in de blaas, wit werden weergegeven: het z.g. "waterplaatje". Af en toe werd een beeld gemaakt waarin nóch T1- nóch T2 invloeden domineerden, maar waarin verschillen in protondichtheid zorgden voor beeldcontrast.

Alras werd het verhaal echter moeilijker: MRI contrastmiddelen werden ontwikkeld welke intraveneus konden worden ingespoten, welke zich ophoopten in normale en abnormale bloedvaten, en ook b.v. tumoren of ontstekingen, en alhier op een T1 gewogen beeld een witte vlek te zien gaven. Om de signaalverhoging ten gevolge van het contrast beter te kunnen onderscheiden van het eveneens hoge signaal van het vet in de omgeving, werden methoden ontwikkeld voor onderdrukking van het vetsignaal: nu zag men alleen nog het hoge signaal van het ingespoten contrastmiddel. Het gevolg is dan wel dat het vetplaatje geen vetplaatje meer is. Op analoge wijze is het mogelijk om het hoge signaal van vrij vloeistof in een T2 gewogen beeld te onderdrukken, waarbij dan het waterplaatje geen waterplaatje meer is. Snelle scantechnieken met aansprekende namen ("turbo"spin-echo) wijzigden ook weer de contrastverhoudingen zodat hetzelfde MRI beeld nu behalve watercontrast óók nog vetcontrast kan bevatten. 
Ik heb mijzelf weleens gefeliciteerd met het feit dat ik met MRI heb leren omgaan toen het allemaal nog zo overzichtelijk was, anders was het er misschien niet eens meer van gekomen!

De ontwikkelingen blijven doorgaan, en MRI is inmiddels de meest krachtige en veelzijdige techniek in ons diagnostisch arsenaal. Afbeelding van de bloedvaten, MR angiografie, heeft zich ontwikkeld tot een serieuze concurrent en gedoodverfde opvolger van de minder patiëntvriendelijke catheterangiografie. Met behulp van contrastversterkte MR angiografie is het nu zelfs mogelijk om bloedvaten van het ruggemerg met een diameter in de orde van $1 \mathrm{~mm}$ af te beelden. Contrastmiddelen worden ook gebruikt om weefseldoorbloeding of perfusie te kwantificeren. Diffusie van vloeistof op moleculair niveau door de weefsels kan op gevoelige wijze worden gedetecteerd, en diffusie gewogen MRI beelden kunnen onder meer worden gebruikt om met behulp van MR tractografie het verloop van de bundels zenuwweefsel in de hersenen en het ruggemerg in kaart te brengen.

Met MR spectroscopie is het mogelijk om de samenstelling van weefselmonsters binnen het levende lichaam te analyseren op grond van z.g. "chemical shifts".

Vroeg in de negentiger jaren werd voor het eerst melding gemaakt van functionele MRI (fMRI) studies welke gebruik maken van verschillen in het regionale zuurstofgehalte van het bloed in de hersenen en tevens hemodynamische veranderingen ten gevolge van de activatie van bepaalde hersengebieden tijdens de uitvoering van bepaalde taken. Aangezien de magnetische eigenschappen van zuurstofrijk bloed verschillen van die van zuurstofarmer bloed, kan op deze wijze in de MRI scanner een (semi)kwantitatieve bepaling worden verricht van locale verschillen in hersenactviteit.

Deze fMRI methode is gebleken een zeer werkzaam instrument te zijn bij fundamenteel hersenonderzoek. De eerste proeven werden uitgevoerd met stroboscopische lichtstimuli, waarbij activatie kon worden vastgesteld van de visuele schorsgebieden, in de achterhoofdskwabben van de hersenen. Later kwamen andere taken: b.v. bewegingsopdrachten welke activatie te zien gaven in de motorische schorsgebieden, gaandeweg steeds meer complexe neuropsychologische taken met betrekking tot b.v. taal, geheugen en cognitie. De methode kan ook worden gebruikt om activatie van neuronen in het ruggemerg zichtbaar te maken. 
Maar nu de keerzijde van de medaille. Door de ontwikkelingen in de beeldvormende techniek, en ook de ontwikkelingen in de geneeskunde als geheel, is de manier waarop wij ons vak uitoefenen ingrijpend veranderd: vroeger was het handwerk, nu lijkt het veel meer op lopende bandwerk.

Een voorbeeld: toen ik in 1976, min of meer bij toeval, als jonge klare neuroloog op de afdeling neuroradiologie in het Academisch Ziekenhuis Groningen kwam te werken, werd het welslagen van een onderzoek bij een patiënt in hoge mate bepaald door de handvaardigheid, en soms de koelbloedigheid, van de onderzoeker. Vooral bij procedures waarbij contrastmiddelen werden toegepast moest eerst een punctienaald of een catheter in de goede lichaamsholte of in het juiste bloedvat worden geplaatst; hiervoor was routine nodig. Vervolgens moest het contrastmiddel op de juiste wijze geïnjecteerd en verdeeld worden: bij een luchtonderzoek van de hersenen kon een iets andere positionering van het hoofd van de patiént betekenen dat de lucht welke in het wervelkanaal werd ingespoten, niet in de hersenkamers terechtkwam, maar in de liquorruimten rondom de hersenen. Bij een myelografie, een afbeelding van het ruggemerg met contrast, kon een verkeerd uitgevoerde beweging of zelfs een hoestbui van de patiént het met zorg ingebrachte contrastmiddel verdunnen en radiologisch onbruikbaar maken. Na een soms met veel moeite uitgevoerd onderzoek was er altijd een gevoel van voldoening wanneer de foto's de gewenste informatie gaven, of een gevoel van ergernis wanneer de resultaten minder fraai waren dan gehoopt.

Met de komst van computertomografie, $\mathrm{CT}$, in de zeventiger jaren begon het al wat meer op lopende bandwerk te lijken. Ingewikkelde manipulaties met de patiënt zijn hierbij niet meer nodig: aan de scannerconsole hoeven alleen maar de knoppen te worden bediend, het apparaat doet, mits goed ingesteld, de rest. Het bedienend personeel moet zorgen voor ongestoorde en gelijkmatige aan- en afvoer van patiënten, als aan een lopende band.

Bovendien ging het tempo steeds meer omhoog. Bij de eerste CT scanners duurde het opnemen van de scan, de radiologische dichtheidsmeting, en het uitrekenen van de meetgegevens en het reconstrueren van het plaatje ongeveer vijf minuten per weefselplak. Bij latere generaties scanners konden op een gegeven moment scantijden per weefselplak van ongeveer 1 seconde worden bereikt. 
Uiteindelijk werd er toe overgegaan het lichaam niet meer te scannen als een stapel opeenvolgende plakken, maar bleef de röntgenbuis roteren terwijl de patiënt langzaam door het scanvlak werd getransporteerd, zodat een spiraal of helix werd afgebeeld. De volgende stap bestond uit het construeren van meerdere rijen detectoren zodat meerdere spiralen tegelijk konden worden gescand. Ook dit begon eerst klein, met twee rijen detectoren, daarna 4, 8 en 16. De nieuwste CT scanner in onze afdeling maakt gebruik van 64 rijen detectoren, en er zijn scanners in aantocht met 256 en zelfs 312 rijen detectoren. De zeer korte scantijden welke hiermee mogelijk zijn, worden toegepast bij onderzoek van bewegende organen zoals het hart.

Het spreekt vanzelf dat met dergelijke scanners in zeer korte tijd gigantische hoeveelheden data worden gegenereerd. Bij een CT onderzoek van borst en buikorganen worden ongeveer 200 plaatjes geproduceerd in een scantijd van ongeveer 10 seconden! Ook bij CT is er een explosieve groei in het aantal verrichtingen is geweest: in 1991 nog 8.255; in 2005 14.562, in 200616.405 en in 2007 17.326. Bij MRI zijn de scantijden in het algemeen langer, maar worden per opname of acquisitie meerdere beelden geproduceerd; aangezien er meestal meerdere acquisities worden verricht kan ook hier het aantal plaatjes dat moet worden bestudeerd, per onderzoek in de tientallen of soms honderden lopen.

I $k$ vertelde reeds dat de beeldvorming op zich slechts het eerste onderdeel is van het "product" beeldvormende diagnostiek. Daarna moeten de beelden worden bestudeerd en geïnterpreteerd door een deskundige op dit terrein. Er moet een verslag worden opgesteld dat naar de verwijzende clinicus wordt gezonden, vaak zal hierna ook nog mondeling overleg plaatsvinden.

In de afgelopen jaren is een toenemende scheefgroei ontstaan tussen het eerste en het tweede deel van het proces. Gedreven door de technische ontwikkelingen en opgejaagd door de wachtlijsten hebben wij de productie van beelden steeds hoger kunnen opvoeren, maar de meest perfecte beelden missen elke diagnostische betekenis wanneer de mankracht en de expertise ontbreken om deze te interpreteren.Er is een toenemend tekort aan radiologen. Berichten uit de Verenigde Staten geven aan dat het aantal radiologische verrichtingen stijgt met $6 \%$ per jaar, maar het aantal radiologen met slechts $2 \%$. In Zweden neemt het aantal verrichtingen met 2-5\% per jaar toe, in het Verenigd Koninkrijk en Canada met 5\%. De oorzaak wordt gezocht in de vergrijzing van de populatie'. 
Behalve het aantal verrichtingen neemt ook de complexiteit van de onderzoeken toe; met name geldt dit voor CT en MRI. De hoogleraar Krestin heeft berekend dat tussen 1988 en 2000 het aantal radiologische verrichtingen met $15 \%$ is toegenomen, maar de werklast per radioloog met $35 \%^{2}$.

Er dreigt nu een situatie te ontstaan, waarbij voor radiologen alle andere werkzaamheden moeten wijken voor de productie van verslagen, het "wegwerken van de stapels".

Toch is het vervaardigen van geschreven verslagen, alhoewel dit een gemakkelijke maat voor "productie" is, niet de belangrijkste activiteit, de "core business" van de radioloog.

De hoogleraar Pattynama, heeft gesteld dat een radioloog niet meer dan $30 \%$ van zijn tijd zou moeten besteden aan het maken van verslagen, en de overige $70 \%$ aan andere activiteiten als "imaging consultant" 3 .

Wat moeten wij ons hierbij voorstellen?

Als beeldvormend consulent is de radioloog intensief betrokken bij alle fasen van het beeldvormend diagnostisch proces. Na ontvangst van een aanvraag voor een onderzoek zorgt hij ervoor dat, afhankelijk van de klinische vraagstelling, de juiste keuze van scanprotocol wordt gemaakt. Voor een MRI onderzoek betekent dit het plannen van een serie opnamen met verschillende karakteristieken, het aantal keuzemogelijkheden is zeer groot. Zo zijn voor een optimaal diagnostisch resultaat bij iedere afzonderlijke vraagstelling van belang: de keuze van contrastweging ( $\mathrm{T}_{1}$, of T2, voor beide opties zijn weer meerdere keuzen mogelijk), toepassing van vetsuppressie of watersuppressie, eventueel injectie van een MR contrastmiddel. Daarnaast nog de keuze van richting en omvang van het afbeeldingsvlak en ook van de dikte van de af te beelden weefselplakken, verder de keuze van het type oppervlaktespoel oftewel radio-antenne. Vaak worden ook, weer afhankelijk van de klinische vraagstelling, nog gespecialiseerde opnamen gepland, b.v. MR angiografie, of MR myelografie, of opnamen met diffusieweging.

De kunst is het hierbij om per klinische vraagstelling een optimaal diagnostisch resultaat te bereiken in een minimale onderzoekstijd. Soms zal hiervoor nog overleg met de verwijzende clinicus nodig zijn; het kan hierna zelfs gebeuren dat het aangevraagde onderzoek niet doorgaat of dat een andere modaliteit wordt gekozen welke meer geschikt is voor het beantwoorden van de vraagstelling. Het spreekt hierbij vanzelf dat de radioloog als beeldvormend deskundige een gedegen klinische achtergrond zal moeten hebben om in een dergelijke discussie als gelijkwaardige gesprekspartner op te kunnen treden. 
Na de uitvoering van het onderzoek vindt schriftelijke verslaglegging plaats. Minstens even belangrijk is echter vaak het mondelinge overleg met de verwijzende clinicus, gezeten voor de lichtkast (thans het beeldscherm) waarbij nuances kunnen worden aangebracht, aanvullende vragen gesteld en nieuwe diagnostische opties overwogen. In een studie van della Palma4 ${ }^{4}$ it 2000 bleek dat tijdens besprekingen tussen radiologen en clinici de aanvankelijke diagnose in 50\% van de gevallen werd veranderd, en de aanvankelijk voorgestelde behandeling in $60 \%$ ! Van Olden wees onlangs in Medisch Contact op het belang van gezamenlijke besprekingen als "vangnet" in geval van communicatiestoornissen tussen radioloog en verwijzer ${ }^{5}$.

Zó behoort ons vak uitgeoefend te worden, en wanneer radiologen zich laten reduceren tot "verslaghengsten" komt ons vak terecht in een marginale en kwetsbare positie.

Verslagen kunnen immers ook in het buitenland worden gedicteerd! Hoe nu te voorkomen dat wij door de toegenomen en steeds verder toenemende druk van het verslagwerk niet meer toekomen aan onze eigenlijke taak als beeldvormend consulent?

De meest voor de hand liggende oplossing is het uitbreiden van de radiologische stafformaties. Toch is het misschien goed om niet ál onze hoop op deze uitkomst te vestigen. Dergelijke uitbreidingen moeten altijd hard worden bevochten en kunnen lang op zich laten wachten, en bovendien moeten er ook voldoende jonge klare radiologen zijn om de nieuwe vacatures in te vullen.

De opleiding van een radioloog kost vijf jaren. Aangezien iedereen het nu wel erover eens is dat binnen ons vak subspecialisatie noodzakelijk is, vooral ook om de rol van beeldvormend consulent naar behoren te vervullen, zou het een stap terug zijn wanneer wij de opleiding zouden inkorten om een vergroting van de uitstroom te bewerkstelligen.

Pogingen om via richtlijnen het aantal aanvragen voor onderzoek terug te brengen, worden door onze klinische collega's meestal met weinig enthousiasme begroet, en andere oplossingen zoals het onverslaan laten van bepaalde categorieën onderzoeken, stuiten op juridische bezwaren.

Wél kunnen taken welke traditioneel worden verricht door radiologen, worden gedelegeerd aan laboranten. Ditgebeurt reeds bijb.v.intraveneuze contrastinjecties en echografisch onderzoek. In het Verenigd Koninkrijk worden al geruime tijd sommige röntgenonderzoeken door daarvoor opgeleide laboranten verslagen; meestal gaat het om skeletfoto's, maar 
ook soms b.v. thoraxonderzoeken ${ }^{6}$.

Tot slot kan men ook het verslagwerk buiten de deur laten doen, in het engels "outsourcing".

Teleradiologie is een betrekkelijk nieuw begrip. Hiermee wordt bedoeld het uitwisselen van digitale beelden via een snelle beeldverbinding, waardoor bij voorbeeld consultatie op afstand of verslaglegging in een ander centrum, zelfs in een ander land kan plaatsvinden.

In de Verenigde Staten zijn z.g. nighthawk diensten ontstaan. De productie van b.v. een MRI afdeling wordt aan het einde van de werkdag verzonden naar een centrum in India, en aldaar dezelfde dag (in de V.S. s'nachts) verslagen zodat de afnemer in de V.S. de volgende ochtend de onderzoekverslagen kant en klaar op zijn werkstation aantreft.

Natuurlijk zijn er juridische obstakels: zo moet de radioloog welke het verslag maakt bevoegd zijn in het land waar de verslagen worden gebruikt. Werktijden in het verslagleggend centrum moeten worden gereglementeerd en de aansprakelijkheid van de radiologen in dit centrum, b.v. in geval van een diagnostische fout, moet worden vastgelegd. Ook moet mogelijk de patient toestemming verlenen voor de outsourcing, en moet de privacy worden beschermd. Controle op de kwaliteit van de verslagen moet worden gewaarborgd.

Veel van deze problemen zijn opgelost of oplosbaar. Het grootste gevaar van outsourcing naar lage lonen landen bestaat echter hieruit dat deze ontwikkeling uitsluitend wordt toegepast om kosten te reduceren door de "eigen" radiologen weg te bezuinigen. Dit is een miskenning van de rol van de radioloog als beeldvormend consulent zoals deze hierboven is uiteengezet, en zal uiteindelijk een funeste invloed hebben op het functioneren van de eigen afdeling radiologie.

Correct toegepast kan outsou rcing van een gedeeltevan de verslaglegging gebruikt worden om piekbelastingen op te vangen en ervoor te zorgen dat de radiologische staf niet bezwijkt onder de dagelijkse last, maar dat er capaciteit blijft om de overige, even belangrijke radiologische taken adequaat te vervullen.

Het is ook goed om te benadrukken dat outsourcing slechts een tijdelijke oplossing kan bieden voor het centrale probleem van de progressieve radiologische onderbezetting welke op komst is. In het noordelijke halfrond vissen de teleradiologie centra in de zelfde vijver als de reguliere radiologische afdelingen, en zullen deze de zelfde problemen gaan ervaren. Uiteindelijk zal dit ook gaan gelden voor een land als India; over China zou ik geen uitspraak durven doen. In derde wereld landen zijn de aantallen radiologen per hoofd van de bevolking zo schrikbarend 
laag dat deze landen eerder afnemers dan leveranciers van expertise zullen blijven.

Bovendien zijn er redenen aan te geven waarom het loskoppelen van de radiologische verslaglegging van de verrichting, duidelijke nadelen heeft:

Bij medische verslagen is de juiste nuancering van belang. Er is een significant verschil in kwaliteit tussen enerzijds een verslag dat is vervaardigd door een radioloog die bekend is met de aanvrager, zijn werkwijze en terminologie, en die gemakkelijk nog even kan overleggen over onduidelijkheden of onverwachte bevindingen, en anderzijds een verslag dat wordt gedicteerd door een radioloog welke alleen beschikking heeft over een vaak cursorisch ingevuld aanvraagformulier van een hem onbekende verwijzer uit een ander taalgebied, van een onderzoek dat is uitgevoerd volgens een scanprotocol waarmee hij zelf niet dagelijks werkt. In het laatste geval is er een groter risico op misverstanden en fouten, of zal de verslaglegger sneller geneigd zijn zich op de vlakte te houden, of aanvullend onderzoek te adviseren. Deze z.g. "downstream costs" komen dan ten laste van het verwijzende centrum. Hetzelfde geldt voor de situatie waarbij de verwijzer na ontvangst van het teleradiologie verslag in tweede instantie de eigen radioloog (als deze er dan nog is!) verzoekt om tóch nog eens het verslag te reviseren.

Bij teleradiologie is discussie tussen de radioloog welke het verslag maakt, en de verwijzende clinicus, in principe wel mogelijk maar wel veel moeilijker en omslachtiger dan wanneer deze zich in dezelfde locatie bevinden. Ook de beschikbaarheid van oude foto's en eerdere verslagen is veel gemakkelijker binnen het eigen ziekenhuis.

Wij accepteren geen onzekerheden meer. Er is een toenemende roep naar steeds meer screeningsonderzoek bij groepen met verhoogd risico voor een bepaalde aandoening.

Tegenwoordig kan men echter nog een stap verder gaan. Er is een nieuwe categorie afnemers van gezondheidszorg aan het ontstaan: de z.g. "worried well", gezond maar bezorgd. Aan deze cliënten (patiënten zijn het vooralsnog niet), wordt een "APK van het lichaam" aangeboden. $\mathrm{Nu}$ is voorkomen altijd beter dan genezen, maar het is toch de vraag of ziekte werkelijk op deze manier kan worden voorkomen, en zo ja, welke nadelen en kosten men op de koop toe moet nemen om één ziektegeval te voorkomen. 
Van Engelhoven heeft over dit onderwerp enkele weken geleden reeds gesproken, en gezien het belang ervan wil ik er ook enkele opmerkingen aan wijden. Ik zal mij meer richten op aspecten van effectiviteit en betrouwbaarheid van dergelijk beeldvormend onderzoek.

Eerst in het algemeen: de diagnostische waarde van een test wordt in sterke mate bepaald door de waarschijnlijkheid dat de aandoening waarnaar wordt gezocht, bij de onderzochte aanwezig is. Dat klinkt als een open deur, maar ik geef $U$ praktisch rekenvoorbeeld dat ik heb geleend van Myriam Hunink, hoogleraar radiologie en klinische epidemiologie te Rotterdam 7.

Wanneer de waarschijnlijkheid dat een bepaalde ziekte aanwezig is, oftewel de prevalentie, laag is, heeft dit een ongunstige invloed op de bruikbaarheid van het testresultaat.

Stel dat de test een sensitiviteit heeft van 90\%. Bij 100 ziektegevallen zal de test dan 90 hiervan correct-positief identificeren en 10 fout-negatief over het hoofd zien.

Behalve de sensitiviteit van een test is ook de specificiteit van belang: het vermogen om gezonde personen correct als gezond te kenmerken. Bij een specificiteit van b.v. $80 \%$ zal de test bij 100 gezonden 80 hiervan correct-negatief bevinden en 20 ten onrechte als ziek: fout-positief. Dit zijn geen ongewone getallen.

Wanneer de kans op ziekte laag is, b.v. 1\%, heeft in een populatie van 1000 personen 10 de ziekte en is 990 gezond. Van de 10 zieken detecteert de test er 9 correct-positief, en wordt 1 gemist. Van de 990 gezonden worden er $80 \%$ oftewel 792 correct als gezond gekenmerkt, echter $20 \%$ of 198 ten onrechte als ziek, fout-positief. Dit is een ratio van correct/fout positief van $1 / 22$ !

De cijfers veranderen wanneer de kans op een ziekte groter is, b.v. 50\%. Van de 500 zieke personen worden er nu 450 (90\%) correct-positief bevonden, en 50 fout-negatief.

Van de 500 gezonden wordt 80\% correct-negatief bevonden: 400 personen, en $20 \%$, oftewel 100 personen fout-positief. De ratio correct/ fout positief is nu $450 / 100$ oftewel $4,5 / 1$, in plats van $1 / 22$ zoals hierboven!

Dit rekenvoorbeeld illustreert hoe sterk de waarde van een test wordt bepaald door het risico op aanwezigheid van ziekte. Is deze laag, zoals bij ongerichte screening, dan gaan de fout-positieven een belangrijke rol spelen. 
Myriam Hunink heeft verder berekend dat bij gelijktijdig screenen op een tweede aandoening met een prevalentie van b.v. $2 \%$, de gecombineerde specificiteit daalt naar $64 \%$ en het aantal fout-positieve bevindingen stijgt naar 550 per 1000. Bij nog uitgebreidere screening zijn er nóg meer fout-positieven. Zij concludeerde dat op een gegeven moment de enige normale onderzochte diegene is die geen volledige screening heeft ondergaan.

Radiologen hebben de grootste moeite bij het interpreteren van toevalsbevindingen. De werkwijze van ongerichte screening richt zich juist op produceren van toevalsbevindingen.

Behalve de fout-positieven moeten wij ons ook zorgen maken over een groter aantal fout-negatieven bij screeningsonderzoek.

Dit heeft te maken met de werkwijze. Niet voor niets verlangen radiologen van hun aanvragers dat zij zo duidelijk mogelijk aangeven wat de waarschijnlijkheidsdiagnose, eventueel differentiaaldiagnose is bij een bepaalde patiënt. Alleen dan kan een gericht scanprotocol worden opgesteld, en dit heeft een gunstig effect op zowel sensitiviteit als specificiteit. Een protocol dat geschikt is voor aantonen van multipele sclerose is vrijwel waardeloos voor de diagnostiek van b.v. epilepsie, of voor het opsporen van een adenoom van de hypofyse.

Bij een brede screeningsopzet is het echter juist nuttig om zoveel mogelijk aandoeningen tegelijk uit te sluiten. Hierdoor zal b.v. het MRI scanprotocol bij een dergelijke screening het karakter van een compromis hebben.

Een voorbeeld uit de literatuur: In een artikel in 2007 beschrijft de auteur $^{8}$ een screeningsstudie bij 1007 personen, waarbij o.m. met MRI afbeeldingen werden gemaakt van de hersenen, het vaatstelsel en het hart en abdomen. Er werden vele afwijkingen gevonden in diverse categorieën, deels binnen en deels buiten mijn vakgebied. Mijn aandacht werd getrokken door de vermelding van de vondst in deze groep van twee patiénten met een cerebraal aneurysma. Een dergelijk aneurysma, een uitstulping door een zwakke plek in de wand van een hersenslagader, kan de oorzaak zijn van een hersenbloeding, en aneurysmata worden nogal eens als toevalsbevinding aangetroffen bij angiografisch onderzoek van de hersenvaten, in percentages welke door de meesten worden geschat op rond 3-6\%, maar volgens sommige auteurs zelfs bij 5-10\% van de populatie als geheel voorkomen 9 . Gelukkig bloeden ze niet allemaal!

Hoe dan ook, het aantal van twee aangetoonde aneurysmata in de 
aangehaalde studie, is veel te laag. Bij ruim 1000 deelnemers hadden er bij de laagste schatting van 3\%, 30 aneurysmata moeten worden gevonden. In deze studie dus minstens 28 fout-negatieve bevindingen. Dit ligt ook wel voor de hand: om een cerebraal aneurysma te detecteren met een afmeting van doorgaans tussen de $3 \mathrm{~mm}$ (een doperwt) en $10 \mathrm{~mm}$ (een tuinboon), moet zeer gericht worden gekeken naar de hersenvaten. Een werkwijze welke beoogt alle lichaamsvaten tegelijk in één onderzoek in kaart te brengen, zal veel kleine details missen.

Screeningsonderzoek heeft zin wanneer gericht gezocht wordt naar een bepaalde aandoening, bij een persoon met een verhoogd risico op deze aandoening. Ongericht onderzoek van gezonde individuen gaat gepaard met belangrijke nadelen. De onderzochte gaat er á priori doorgaans vanuit dat "alles wel goed zal zijn". Wanneer er wél iets wordt gevonden, is Leiden in last. Het zal ongetwijfeld sporadisch voorkomen dat bij ongerichte screening een toevalsafwijking wordt gevonden waarvoor in een vroege fase een levensreddende behandeling mogelijk is. Hier staat tegenover een veelvoud aan fout-positieve bevindingen welke aanleiding zijn tot veel onrust, onzekerheid en overbodig vervolgonderzoek.

In het geval dat na de screening wordt meegedeeld dat "alles in orde" is, biedt dit vaak een schijnzekerheid, gezien het grote risico op foutnegatieve bevindingen.

Ik vind het prima om een periodiek ongericht screeningsonderzoek de beschrijven als een "APK van het lichaam". Maar zeg er dan wel bij dat bij deze APK na afloop vaak het advies wordt gegeven om voor de zekerheid nog wat verder onderzoek te laten doen, b.v. het demonteren van de versnellingsbak of inspecteren van de remvoeringen, wat achteraf niet nodig blijkt te zijn geweest. Bovendien moet dan ook worden vermeld dat de bandenspanning en de stand van de spiegels weliswaar worden gecontroleerd, maar dat de motorkap maar half open gaat en dat de monteur zijn bril heeft thuisgelaten.

Ik kom tot mijn dankwoord. Ik dank:

Om te beginnen natuurlijk Jelleke, voor de afgelopen achttien jaren en voor al het andere.

Verder ga ik niet iedereen noemen, omdat ik niet iedereen kán noemen. In ieder geval wel Jos van Engelshoven, die mij achttien jaar geleden naar het mooie Limburgse land heeft gehaald.

Paul Hofman, meedenker en meewerker van het eerste uur, die zich ook in de laatste weken en dagen zo enorm heeft ingespannen om deze afscheidsfeestelijkheden zo goed te laten verlopen. 
De radiologische stafleden en de laboranten. Ik heb in de loop van de jaren met genoegen de groei en uitbouw gezien van een hooggekwalificeerde en professionele organisatie die zich op alle terreinen kan meten met die van onze vakbroeders in binnen- en buitenland.

De medewerkers van de administratie en het secretariaat, die altijd klaarstonden om dringende verzoeken om hulp en bijstand, meestal op het laatste moment kenbaar gemaakt, zonder zichtbaar zuchten of steunen te honoreren. Ik denk hierbij vooral aan Ine Kengen.

Tenslotte de assistenten in opleiding en onderzoekers. Ik heb mij altijd fortuinlijk geprijsd dat ik zo vele getalenteerde jonge collega's op mijn weg heb gevonden van wie ik zoveel heb geleerd, van de assistenten vooral om altijd goed na te blijven denken. Ik heb met bewondering de gedrevenheid gadegeslagen warmee de jonge onderzoekers op onze afdeling zich inzetten voor hun projecten, en heb respect voor de kwaliteit van de wetenschappelijke productie welke door hen wordt geleverd.

Het doet mij deugd dat zo velen gevolg hebben gegeven aan mijn uitnodiging om dit college bij te wonen.

Dames en heren,

Het was mij een eer en een genoegen 


\section{Referenties:}

1. Jersild S. Radiologist sightings drop around the world. Diagnostic Imaging 2003 Juli: 15-18

2. Krestin GP. Creative solutions can help alleviate staff shortages. Diagnostic Imaging Europe 2004 April: 48

3. Pattynama P. Radiology must confront outsourcing challenges. Diagnostic Imaging Europe 2006 April: 40

4. Della Palma L, et. al. Relationships between radiologists and clinicians: results of three surveys. Clinical Radiology 2000; 55: 602-605

5. van Olden G, et. al. Foto gemist: claim aan de broek. Medisch Contact 2008, 63, 5: 642-643

6. Thomas AMK, Manning D, Piper K. UK forges ahead with radiographer reporting. Diagnostic Imaging Europe 2004 Februari: 45-49.

7. Hunink M. Gould P.Whole-body imaging needs more tailored approach to be effective. Diagnostic Imaging Europe 2007, Aug/Sep:5-6

8. Baumgart D, Egelhof T. Präventives Ganzkörperscreening unter Einbeziehung moderner Bildgebung mit Hilfe der MR tomographie. Herz 2007 Aug;32(5): 387-394

9. Wardlaw JM, White PM. The detection and management of unruptured intracranial aneurysms. Brain 2000; 123: 205-221 

